\section{Mastronardi \\ A. Guiducci \\ D. Frondizi \\ S. Carletti \\ C. Spera \\ G. Maira}

\title{
Intraneural capillary hemangioma of the cauda equina
}

Received: 24 August 1996

Revised: 2 December 1996

Accepted: 17 December 1996

L. Mastronardi - D. Frondizj - S. Carletti

C. Spera · G. Maira

Neurosurgery Unit,

Department of Neurological Sciences,

Civilian Hospital "Santa Maria",

Terni, Italy

A. Guiducci

Institute of Pathological Anatomy,

Terni, Italy

L. Mastronardi ( $\square)$

Via Archimede 120, I-00197 Rome, Italy

Tel.: +39-6-8551729; Fax: +39-6-3216925

e-mail: mastr@mbox.vol.it

\begin{abstract}
A case of intraneural capillary hemangioma involving the dorsal root of a spinal nerve of the cauda equina is reported. The patient was a 41-year-old man with a 3-month history of intermittent left lumbosciatalgia. MRI and CT myelography showed a space-occupying mass at the level of the cauda equina. Laminectomy of L5 and complete removal
\end{abstract}

of the lesion were performed without neurological problems. The clinical, diagnostic, and therapeutic aspects of hemangiomas of the cauda equina are analyzed.

Key words Cauda equina . Intraneural hemangioma $\cdot$ Spine surgery

\section{Introduction}

Solitary intraneural hemangiomas, that is, angiomas arising within the boundaries of the nerve, are very rare $[4,5,8$, $10,11,13]$. Also extremely rare are vascular lesions involving one or more roots of the caude equina $[1-3,6,7,9,12]$.

We present a case of intraneural capillary hemangioma arising with the boundaries of the sheath of the dorsal root of a lumbar spinal nerve. To our knowledge, this is the first such case described in the literature.

\section{Case report}

A 41-year-old man presented with a 3-month history of intermittent low-back pain radiated on the posterior lateral surface of the left inferior limb. During the previous weeks the pain had worsened, with consequent gait and work difficulties.

\section{Examination}

On admission, neurological examination revealed no abnormalities except for a $30^{\circ}$ left a $45^{\circ}$ right straight leg raising test and a slightly hypoactive left ankle jerk. There was no motor nor sensory deficit in the inferior limbs. Sphincter control was normal.

Lumbosacral MRI revealed an intradural space-occupying lesion at the $\mathrm{L} 5$ level, with a maximum diameter of $1.5 \mathrm{~cm}$. The lesion appeared slightly hyperintense on $\mathrm{T} 1$-weighted images and isointense on T2-weighted images (Fig. 1). Lumbar CT myelography showed a filling defect corresponding to L5, with delineation of a round, irregular, left subdural mass, enhancing after administration of IV contrast medium.

\section{Operation}

The patient was operated on with a presumptive diagnosis of neurinoma of the cauda equina. An L5 laminectomy was performed. When the dura was opened, a pink-grayish soft mass, measuring about $1.5 \times 1 \times 1 \mathrm{~cm}$, was found within the boundaries of the dorsal root of the L5 spinal nerve, continuing towards the respective intervertebral foramen. After having opened the enlarged dorsal root on the posterior aspect, total removal of the mass was possible only by sacrifying the nerve fibers arranged around the posterior aspect of the lesion and strongly adherent to it. However, microsurgical dissection of the nerve fibers disposed around the anterior aspect of the mass was possible without sacrifying them.

The postoperative course was uneventful and only a partial L5 sensory deficit was observed. A few days later the patient was discharged without pain, and 1 month later he returned to work without problems. 

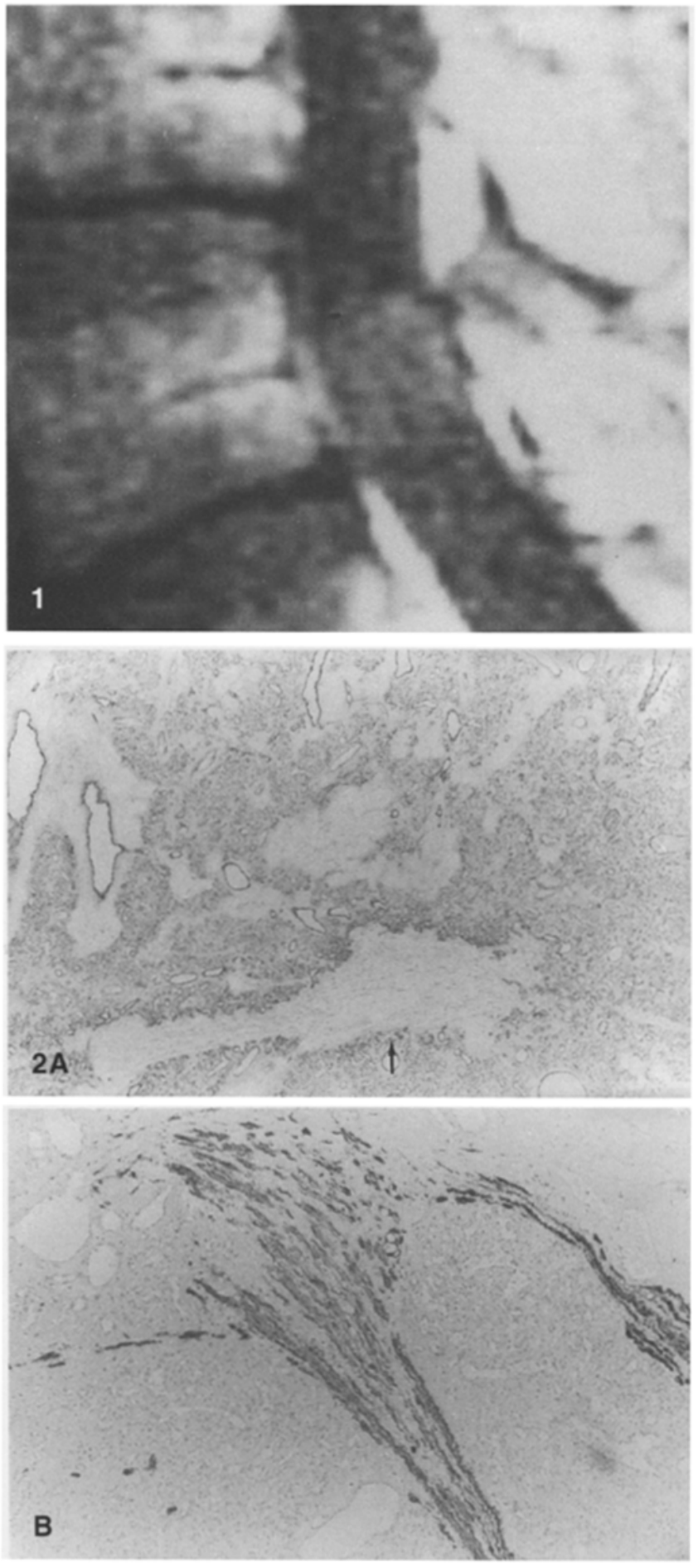

Fig. 1 Lumbosacral MRI reveals an intradural space-occupying lesion at the L5 level, slightly hyperintense of T1-weighted images

Fig. 2 A, B Histopathological photomicrographs. A Factor VIIIassociated antigen immunostain, $\times 100$ : capillary hemangioma arising within the root sheath of the spinal nerve. The arrow indicates the residual nerve fibers. B S-100 immunostain, $\times 100$ : remnants of the myelinated nerve, dissociated by proliferating capillary vessels

\section{Pathological examination}

Grossly, the specimen revealed an expanded nerve trunk that formed a pale gray nodule of fusiform shape, measuring $1.2 \times 0.7$ $\times 0.7 \mathrm{~cm}$. The appearance was indistinguishable from that of a conventional schwannoma.

Samples were fixed in $10 \%$ buffered formalin and embedded in paraffin. Sections were stained with hematoxylin and eosin and by Masson's trichrome technique. Immunohistochemical studies were also performed with the avidin-biotin-peroxidase complex (ABC) technique. The following anti-sera were used: factor VIII-related antigen (Dako) for the endothelial component; S-100 protein; and neurofilament (Dako) for the neural component.

Microscopic examination showed the nerve trunk to be occupied by a vascular neoplasm that lay within the boundaries of the root sheath, characterized by the presence of a myriad of small capillary-sized vessels, extending between atrophied nerve fascicles (Fig. 2A). The arrangement of the tumor was lobular, with roundish aggregates of capillaries separated by edematous intervening tissue of fibrous connective septa.

Although inconspicuous, a lumen formation was apparent in almost all capillaries, which were lined by plump endothelial cells. Mitotic figures were absent. Residual nerve fibers interspersed with capillary lobules were barely discernible and were best emphasized by employing specific immunohistochemical stains (Fig. 2 B).

On the basis of this information, the histopathological diagnosis was intraneural capillary hemangioma.

\section{Discussion}

Solitary intraneural hemangiomas, that is, angiomas arising within the boundaries of a nerve trunk, are extremely rare vascular lesions. On reviewing the literature, Wood [13] found only nine cases previously described in detail. Involved nerves included median $[4,10]$, peroneal [11], posterior tibial [11], trigeminal [5], and ulnar [5]. Pain is the most common symptom, often accompanied by numbness, paresthesias, hypoesthesia, and muscle wasting in the affected region $[4,5,10,11,13]$.

Vascular lesions involving one or more roots of the cauda equina are also extremely rare. After the incidental finding observed necroscopically by Hadlich in 1903 [2], the first clinical case was reported in detail by Hirsch et al. [3] about 30 years ago. The authors completely excised a small black berry-like lesion adherent to several roots of the cauda equina in a 20 -year-old man suffering from intermittent pain, inferior limb motor deficit, saddle anesthesia, and sphincteric disturbances. After that, another five cases were reported $[1,6,7,9,12]$.

Table 1 summarizes the cases of hemangiomas of the cauda equina previously reported in detail, as well as our own case. With the exception of our case report, on histological examination the vascular lesion is generally described as a cavernous angioma. The mean and the median age are respectively 40 and 41 years (ranging from 20 to 67 years). Six patients are male and one female. Intermittent low-back pain radiated on inferior limbs is reported in five of the seven cases collected. weakness of deep tendon reflexes in three, loss of sphincter control in three (including a case with normotensive hydrocephalus) 
Table 1 Hemangiomas of the cauda equina reported in the literature ( $S A$ saddle anesthesia, $I L M D$ inferior limb motor deficits, $S I$ sphincteric incontinence, $L S$ lumbosciatalgia, $A J$ absence or reduc- tion of ankle jerks, $S A H$ subarachnoid hemorrhage, $G D$ gait disturbances, cogn dys cognitive dysfunction, NP normal pressure, filum ter filum terminale; capillary hem capillary hemangioma)

\begin{tabular}{|c|c|c|c|c|c|c|c|c|}
\hline Author, year & Sex & Age & Clinical data & Level & Root & Histology & Removal & Result \\
\hline Hirsch et al. [3], 1965 & M & 20 & $\begin{array}{l}\text { Intermittent pain in the } \\
\text { caudal area, SA, ILMD, SI }\end{array}$ & L2-L3 & $?$ & Cavernoma? & Total & Good \\
\hline Pansini, Lo Re [7], 1966 & M & 46 & $\begin{array}{l}\text { Intermittent LS, SA, -AJ, } \\
\text { SI, ILMD }\end{array}$ & L1-L2 & $?$ & Cavernoma? & Total & Fair \\
\hline Ueda et al. [12], 1987 & M & 28 & SAH & L1-L2 & $?$ & Cavernoma & Total & Good \\
\hline Pagni et al. [6], 1990 & M & 46 & Sudden LS, -AJ & D12-L1 & $?$ & Cavernoma & Total & Good \\
\hline Ramos et al. [9], 1990 & $\mathrm{~F}$ & 67 & $\begin{array}{l}\text { GD, cogn dys, SI } \\
\text { (NP hydrocephalus) }\end{array}$ & L3 & filum ter & Cavernoma & Total & Good \\
\hline Acciarri et al. [1], 1993 & M & 31 & $\begin{array}{l}\text { Intermittent radicular } \\
\text { symptoms }\end{array}$ & $\mathrm{L} 2$ & $?$ & Cavernoma & Total & Good \\
\hline Present case, 1997 & M & 41 & Intermittent LS, -AJ & L5 & L5 & Capillary hem & Total & Good \\
\hline
\end{tabular}

[9], motor deficits in the inferior limbs in two, sensory disturbances in two, intermittent radicular pain in one [1], subarachnoid hermorrhage in one [12], and hydrocephalus with normal pressure in one [9]. With the exception of the case reported by Ramos et al. [9], in which the filum terminale is involved, and of our own case, which involved the dorsal root of the L5 spinal nerve, none of the other reported cases specify involvement of the spinal nerve or nerves by the vascular malformation. The vertebral level of the lesion is L2 in two cases, T12-L1 in one case, L1-L2 in one case, L2-L3 in one case, L3 in one case, and $\mathrm{L} 5$ in our own case. In all cases a laminectomy was performed and total removal of the hemangioma was achieved. In all but one case [7] a good or excellent outcome was been obtained.
To our knowledge, this is the first reported case of intraneural capillary hemangioma, that is, a vascular malformation formed by capillary-sized vessels, involving the root of a spinal nerve of the cauda equina. The preoperative clinical, neuroradiological (Fig. 1), and surgical presumptive diagnosis was schwannoma involving the cauda equina; the correct diagnosis was possible only after histopathological examination (Fig. 2). In fact, the symptoms and signs and the information provided by MRI and CT myelography provided an inadequate basis for formulating this particular diagnosis.

The treatment of intraneural hemangiomas and of hemangiomas of the caude equina consists in surgical removal of the vascular malformation. With the microsurgical technique, total excision is generally possible without morbidity.

\section{References}

1. Acciarri N, Padovani R, Giulioni M, Gaist G (1993) Surgical treatment of spinal cavernous angioma. $J$ Neurosurg Sci 37:209-215

2. Hadlich R (1903) Ein Fall von Tumor Cavernosus des Rückenmarks mit besonderer Beriicksichtigung der neueren Theorien über die Genesis des Kavernom. Virchows Arch 172:429 441

3. Hirsch JF, Pradat P, David M (1965) Angiome caverneux de la queue de cheval. Neurochirurgie 11:323-327

4. Kojima T, Ide Y, Marumo E (1976) Hemangioma of median nerve causing carpal tunnel syndrome. Hand 8:62-63
5.Losli EJ (1952) Intrinsic hemangiomas of the peripheral nerves. Arch Pathol $53: 226$

6. Pagni CA, Canavero S, Forni M (1990) Report of a cavernoma of the cauda equina and review of the literature. Surg Neurol 33:124-131

7. Pansini A, Lo Re F (1966) Raro caso di angiocavernoma della cauda. Mem Soc Tos Um Chir 27:679-696

8. Purcell FH, Gurjian ES (1945) Hemangioma of the peripheral nerves. Ann J Surg $30: 541$

9. Ramos F Jr, De Toffol B, Aesch B, Jan M (1990) Hydrocephalus and cavernoma of the cauda equina. Neurosurgery $27: 139-142$
10. Sato S (1913) Uber das cavernöse Angiom des peripherischen Nervensystem. Arch Klin Chir 100:553-555

11. Summer R (1992) Über cavernöse Angiome am peripheren Nervensystem. Dtsch Z Chir 173:65-67

12. Ueda S, Saito A, Inomori S, Kim I (1987) Cavernous angioma of the cauda equina producing subarachnoid hemorrhage. J Neurosurg 66:134-136

13. Wood MB (1980) Intraneural hemangioma: report of a case. Plast Reconstr Surg 65:74-76 